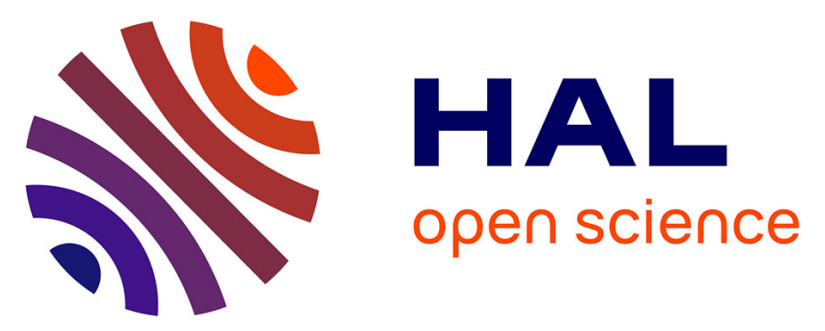

\title{
Time trends in the reporting of conflicts of interest, funding and affiliation with industry in intensive care research: a systematic review
}

\author{
Michael Darmon, Julie Helms, Audrey de Jong, Peter Buhl Hjortrup, \\ Emmanuel Weiss, Anders Granholm, Riccardo Pinciroli, Charlotte \\ Poussardin, Marie Warrer Petersen, Stéphanie Sigaut, et al.
}

\section{To cite this version:}

Michael Darmon, Julie Helms, Audrey de Jong, Peter Buhl Hjortrup, Emmanuel Weiss, et al.. Time trends in the reporting of conflicts of interest, funding and affiliation with industry in intensive care research: a systematic review. Intensive Care Medicine, 2018, pp.1669-1678. 10.1007/s00134-0185350-2 . hal-01863814

\section{HAL Id: hal-01863814 \\ https://hal.umontpellier.fr/hal-01863814}

Submitted on 9 Jan 2020

HAL is a multi-disciplinary open access archive for the deposit and dissemination of scientific research documents, whether they are published or not. The documents may come from teaching and research institutions in France or abroad, or from public or private research centers.
L'archive ouverte pluridisciplinaire HAL, est destinée au dépôt et à la diffusion de documents scientifiques de niveau recherche, publiés ou non, émanant des établissements d'enseignement et de recherche français ou étrangers, des laboratoires publics ou privés. 


\title{
Time trends in the reporting of conflicts of interest, funding and affiliation with industry in intensive care research: a systematic review
}

Michael Darmon ${ }^{1,2,3^{*}}$ D , Julie Helms ${ }^{4,5}$, Audrey De Jong ${ }^{1,6}$, Peter Buhl Hjortrup ${ }^{7,8}$, Emmanuel Weiss ${ }^{9,2}$, Anders Granholm7, Riccardo Pinciroli ${ }^{10}$, Charlotte Poussardin ${ }^{4}$, Marie Warrer Petersen ${ }^{7}$, Stéphanie Sigaut ${ }^{8}$, Bruna Brandao Barreto ${ }^{1,11}$, Morten Hylander Moller ${ }^{7}$ and Elie Azoulay ${ }^{1,2,3}$

\begin{abstract}
Purpose: Conflict of interest (COI) may compromise, or have the appearance of compromising, a researcher's judgment or integrity in conducting or reporting research. We sought to assess time trends of COl and funding statement reporting in the critical care literature.

Methods: PubMed was searched by using Medical Subject Headings and the appropriate corresponding keywords: "INTENSIVE CARE UNIT" or "ICU" as a major topic. Four years in a 15-year time period (2001-2016) were arbitrarily chosen and one study month was randomly selected for each study period. Studies published during the selected months were included in the analysis.

Results: Three hundred and seventy-four studies were evaluated, including five reviews (1.3\%) and ten randomized clinical trials (RCTs) (2.7\%). COI statements were available in $65 \%$ of the studies and $8 \%$ had declared COI. COI statement rate, declared $\mathrm{COI}$ and funding statements increased over time, while the number of authors affiliated with industry and the discordance between the lack of COI statement and affiliation with industry decreased. Declared COI were more frequent in 2011-2016 as compared to 2001-2010 (OR 4.06; 95\% Cl 1.15-25.79) and in the higher quartile of a journal's impact factor (OR of $16.73 ; 95 \% \mathrm{Cl} 3.28-306.20$ ). Surprisingly, focus of the study, country of the first author and/or endorsement of the study by a trial group were not associated with COI statements.
\end{abstract}

Conclusion: Our study suggests COI reporting to have been unintuitive to most investigators and unreliable before ICMJE statements, and that strong incentives are needed to implement adequate reporting of COI.

Keywords: Bibliometrics, Conflicts of interest, Disclosure/statistics and numerical data, Editorial policies, Journal impact factor, Periodicals as topic/standards, Bias

\section{Introduction}

Conflict of interest (COI) involves a situation in which faculty or staff has financial or other personal considerations that may compromise, or have the appearance of

*Correspondence: michael.darmon@aphp.fr

'Medical ICU, Saint-Louis University Hospital, AP-HP, 1 Avenue Claude Vellefaux, 75010 Paris, France

Full author information is available at the end of the article compromising, their professional judgment or integrity in teaching, clinical care, conducting or reporting research. Patients trust their doctor and rightly expect them to act in their best interest. Similarly, as medical publishing intends to transfer knowledge that ultimately translates into improved quality of care, patients should be confident that decisions regarding their care are not influenced by the self-interest of their health care providers. Concerns that $\mathrm{COI}$ can bias interpretation and reporting of scientific research and care strategies have increased 
over the past decade [1]. The involvement of the pharmaceutical industry in medical research has considerably increased, leading to financial ties of this industry, either directly to researchers or through research grants to their institutions [1-5]. Whether these financial ties might affect scientific findings is established. For instance, COI is associated with change in study design, conduct, and reporting of studies that may influence findings [6]. Also, COI might affect research priorities, publication, teaching and medical education, and clinical decision making [7]. COI play a role in the assessment of peer-reviewers and editors of journals. Thus, COI being a potential bias, its disclosure may allow adequate interpretation of study results $[7,8]$.

Nearly 10 years ago, the Institute of Medicine (IOM) defined COI as "a set of circumstances that creates a risk that professional judgment or actions regarding a primary interest (integrity of research, welfare of patients, quality of medical education) will be unduly influenced by a secondary interest (financial gain, professional advancement, personal achievement, different favors)" [9]. The need to protect the integrity of clinical research has, therefore, arisen [10] and led to an attempt to control such [10-12].

For researchers, transparent and thorough reporting of COI has been advocated [10,13-15]. In this context, the World Association of Medical Editors (WAME) and the International Committee of Medical Journal Editors (ICMJE) have developed a disclosure form, which has been adopted by all ICMJE journals $[1,16]$.

We aimed to systematically assess time trends of COI reporting in the critical care literature since the millennium, and furthermore identify factors associated with the reporting of COI. We hypothesized that COI reporting has increased over the years, and that journal and study related factors would be associated with disclosure of COI.

\section{Methods}

This systematic review was performed according to the guidelines of Preferred Reporting Items for Systematic Reviews and Meta-Analyses (PRISMA) statement [17]. We did not register the review at PROSPERO, as it was unrelated to health outcomes (https://www.crd.york. ac.uk/prospero/\#aboutpage).

An internal protocol and statistical analysis plan was prepared prior to beginning the study.

\section{Definitions}

COI statements: An explicit statement about the presence or absence of $\mathrm{COI}$ in the manuscript.

Declared COI: An explicit statement confirming presence of financial or non-financial COI.
Authors' affiliation to industry: A self-reported affiliation to any private company.

Discordance between a declared COI and affiliation to industry: The presence of any affiliation to industry without an explicit statement of this as a COI.

\section{Search strategy and eligibility criteria}

PubMed was searched by using Medical Subject Headings (MESH) and the appropriate corresponding keywords: "INTENSIVE CARE UNIT" OR "ICU" as major topic. Four periods of 1 month in 15 years were decided a priori. Years were chosen arbitrarily $(2001,2006,2011$, 2016) and study month was randomly selected for each study period (November 2011, April 2006, August 2011 and September 2016). Studies published during the selected months were included in this analysis.

References were then downloaded for consolidation, elimination of duplicates, and further analysis. All study designs were included. Articles were evaluated by 11 authors (AD, EW, JH, MH, PH, MD, BB, CP, MP, SS, AG). Studies with explicit redundancies were only included once and studies in languages other than English were excluded.

\section{Data extraction and quality control}

Eleven authors (AD, EW, JH, MH, PH, MD, BB, CP, MP, SS, AG) carried out data extraction. Disagreements were resolved with discussion among authors. Also, a 10\% random selection of the included manuscripts was rechecked and the correlation between the extracted data was assessed.

For each included study, we extracted the following information:

Journal characteristics: Publisher, continent, focus, open access journal, and IF.

Study characteristics: Design, focus, sample size, a statistically significant effect in the primary outcome analysis, number of authors, and a trial group as co-author.

$\mathrm{COI}$ and affiliation to industry: COI statement, declared $\mathrm{COI}$, affiliation to industry, study funding, type of $\mathrm{COI}$, type of funding, discordance between $\mathrm{COI}$ and affiliation.

\section{Statistical analysis}

The statistical analyses were conducted according to a pre-defined analysis plan. Any modifications to the planned analysis are called post hoc analyses. Results are reported as medians with interquartile ranges (IQRs) or numbers (percentages) as appropriate. Comparisons were performed using Chi-squared test or Fisher's exact 
test for categorical variables or Wilcoxon rank-sum test for continuous variables.

For quality control, $10 \%$ of the dataset was randomly recoded and correlation (continuous variables) or concordance (Cohen's kappa coefficient-binary variables) reported.

We used binary logistic regression analyses to assess the independent association between journal and study characteristics and the presence of a COI statement (primary analysis 1) and with the presence of declared COI (secondary analysis). Variables of interest were selected a priori according to their relevance and statistical significance in univariate analysis. We used conditional stepwise regression with 0.2 as the critical $P$ value for entry into the model, and 0.1 as the $P$ value for removal. Interactions and correlations between the explanatory variables were carefully checked. Continuous variables for which log-linearity was not confirmed were transformed into categorical variables according to median or IQR. The final models were assessed by calibration, discrimination and relevancy. Residuals were plotted and the distributions inspected.

All tests were two-sided, and $P$ values less than 0.05 were considered statistically significant. Analyses were done using R software version 3.4.4 (https://cran.r-proje ct.org/).

\section{Results}

The search yielded 427 citations, of which 25 were excluded, as no full-text could be obtained, and 28 were excluded as they were not in English. Accordingly, 374 studies were included and evaluated (Fig. 1).

\section{Quality control}

We re-checked $10 \%$ of the dataset (Table S1). Overall, the concordance was above $80 \%$ for categorical discrete variables and $90 \%$ for continuous variables. Four variables however, had lower concordance rates: focus of the study (74\%; 95\% CI 58-87\%), study sample size $(r=0.41$, $P=0.01$ ), type of funding (concordance of $34.2 \%$; $95 \% \mathrm{CI}$ $20-51 \%$ ) and number of declared grants (concordance of $55.3 \%$; 95\% CI 38-71\%).

\section{Characteristics of the included studies}

Twenty-seven studies were published in 2001, 77 in 2006, 113 in 2011, and 161 in 2016.

Characteristics of the studies are reported in Table 1. The number of studies published in open-access journals increased steadily over the years from 4.3 to $32.9 \%$, as well as the median IF. The design of the studies did not change over time, with the minority of studies being systematic reviews $(n=5,1.3 \%)$ and randomized clinical trials (RCTs) $(n=10,2.7 \%)$. Study sample size increased

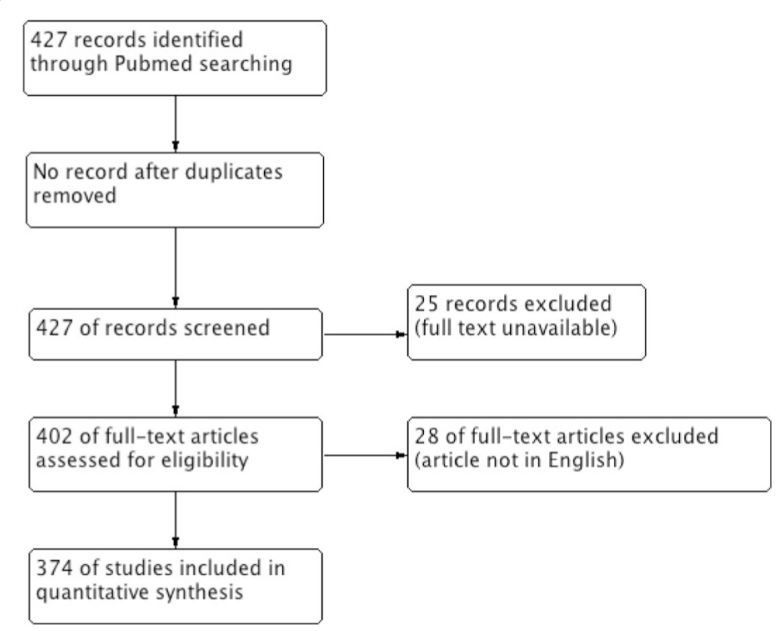

Fig. 1 Flow chart of study selection

steadily over the years from median ten subjects (0-494) in 2001-134 (27-739) in 2016.

\section{Statement of COI, funding and affiliation with industry}

Overall, COI statements were available in $65 \%$ of the studies and 29/374 studies (7.7\%) reported COI (Table 1).

The rate of COI statements, declared $\mathrm{COI}$ and funding statements increased progressively over time (Table 1, Fig. 2, Fig. S1, Fig. S2). The vast majority of COI statements were financial COI or ties with industry $(26 / 30$, 86.7\%).

Factors associated with a COI statement by univariate analyses are reported in Table 2. Overall, the COI rate varied according to journal characteristics (focus of the journal, year of publication, journal impact factor), but also with study characteristics (namely design of the study, and number of authors) (Fig. 3). The number of authors affiliated to industry, as well as discordance between the COI statement and affiliation with industry decreased over time (Table 1, Fig. S3).

After adjusting for potential confounders (Fig. 4), COI statements were more frequent in 2011 (OR 139.2; 95\% CI 25.6-2612.8) and 2016 (OR 101.7; 95\% CI 19.31887.6) as compared to 2001, more frequent in higher quartile of IF (OR of 4.26; 95\% CI 1.72-1.11) and in open access journals (OR 2.28; 95\% CI 1.03-5.39). No correlations or interactions between the explanatory variables were detected and variance inflation factor was lower than 1.5 for all of the included variables. HosmerLemeshow goodness of fit $\mathrm{C}$-stat test was performed $(P$ value $=0.40)$ and area under the receiver operating characteristic (ROC) curve of the model was of 0.85 . Other variables significantly associated with $\mathrm{COI}$ in univariate analysis were not retained in the final model. 
Table 1 Characteristics of journals and studies according to publication period [reported as number (\%) or median (IQR)]

\begin{tabular}{|c|c|c|c|c|c|}
\hline & $\begin{array}{l}2001 \\
n=23\end{array}$ & $\begin{array}{l}2006 \\
n=77\end{array}$ & $\begin{array}{l}2011 \\
n=113\end{array}$ & $\begin{array}{l}2016 \\
n=161\end{array}$ & $P$ value \\
\hline \multicolumn{6}{|l|}{ Journal and publisher characteristics } \\
\hline Continent & & & & & $<0.001$ \\
\hline Africa & $0(0.0 \%)$ & $1(1.7 \%)$ & $0(0.0 \%)$ & $0(0.0 \%)$ & \\
\hline Asia & $0(0.0 \%)$ & $6(10.0 \%)$ & $2(2.4 \%)$ & $4(2.5 \%)$ & \\
\hline Australia & $0(0.0 \%)$ & $2(3.3 \%)$ & $0(0.0 \%)$ & $2(1.2 \%)$ & \\
\hline Europe & $10(43.5 \%)$ & $19(31.7 \%)$ & $38(45.2 \%)$ & $66(41.0 \%)$ & \\
\hline N. America & $13(56.5 \%)$ & $31(51.7 \%)$ & $42(50.0 \%)$ & $74(45.0 \%)$ & \\
\hline Oceania & $0(0.0 \%)$ & $0(0.0 \%)$ & $2(2.4 \%)$ & $3(1.9 \%)$ & \\
\hline South America & $0(0.0 \%)$ & $1(1.7 \%)$ & $0(0.0 \%)$ & $12(7.5 \%)$ & \\
\hline Focus of the journal & & & & & $<0.001$ \\
\hline Generalist & $10(43.5 \%)$ & $15(19.5 \%)$ & $38(33.6 \%)$ & $77(47.8 \%)$ & \\
\hline $\mathrm{ICU}$ & $7(30.4 \%)$ & $18(23.4 \%)$ & $52(46.0 \%)$ & $35(21.7 \%)$ & \\
\hline Other & $6(26.1 \%)$ & $12(15.6 \%)$ & $23(20.4 \%)$ & $0(0.0 \%)$ & \\
\hline Specialist non ICU & $0(0.0 \%)$ & $32(41.6 \%)$ & $0(0.0 \%)$ & $49(30.4 \%)$ & \\
\hline Open access journal & $1(4.3 \%)$ & $11(14.9 \%)$ & $18(15.9 \%)$ & $53(32.9 \%)$ & $<0.001$ \\
\hline Impact factor & $1.96(0.52,2.31)$ & $1.27(0.00,2.44)$ & $2.13(1.50,4.61)$ & $1.98(1.31,3.27)$ & 0.001 \\
\hline \multicolumn{6}{|l|}{ Article characteristics } \\
\hline Type of study & & & & & 0.637 \\
\hline Other & $23(100.0 \%)$ & $75(97.4 \%)$ & $107(94.7)$ & $154(95.7 \%)$ & \\
\hline $\mathrm{RCT}$ & $0(0.0 \%)$ & $1(1.3 \%)$ & $3(2.7 \%)$ & $6(3.7 \%)$ & \\
\hline SR/MA & $0(0.0 \%)$ & $1(1.3 \%)$ & $3(2.7 \%)$ & $1(0.6 \%)$ & \\
\hline Focus of the study & & & & & $<0.001$ \\
\hline Device & $1(4.3 \%)$ & $7(9.1 \%)$ & $11(9.7 \%)$ & $14(8.7 \%)$ & \\
\hline Drugs & $1(4.3 \%)$ & $14(18.2 \%)$ & $6(5.3 \%)$ & $5(3.1 \%)$ & \\
\hline Other & $11(47.8 \%)$ & $49(63.6 \%)$ & $55(48.7 \%)$ & $104(64.6 \%)$ & \\
\hline Strategy & $10(43.5 \%)$ & $7(9.1 \%)$ & $41(36.3 \%)$ & $38(23.6 \%)$ & \\
\hline Review or editorial & $11(47.8 \%)$ & $0(0.0 \%)$ & $4(3.5 \%)$ & $27(16.8 \%)$ & $<0.001$ \\
\hline Study sample & $10(0,494.5)$ & $247(66,1249)$ & $224(48,1007)$ & $134(27,739)$ & 0.004 \\
\hline Observed statistical significance & $9(39.1 \%)$ & $9(11.7 \%)$ & $46(40.7 \%)$ & $34(21.1 \%)$ & $<0.001$ \\
\hline Number of authors & $3(1.5,6.5)$ & $4.00(2,6)$ & $5.00(4,6)$ & $5(4,7)$ & 0.001 \\
\hline Study endorsed by a trial group & $3(13.0 \%)$ & $8(10.4 \%)$ & $5(4.4 \%)$ & $14(8.7 \%)$ & 0.327 \\
\hline \multicolumn{6}{|c|}{ Conflict of interest and authors affiliated to industry } \\
\hline COl Statement & & & & & $<0.001$ \\
\hline Declared COI & $1(4.3 \%)$ & $1(1.3 \%)$ & $10(8.8 \%)$ & $17(10.6 \%)$ & \\
\hline Declared absence of COI & $0(0.0 \%)$ & $8(10.4 \%)$ & $88(77.9 \%)$ & $118(73.3 \%)$ & \\
\hline No statement & $22(95.7 \%)$ & $68(88.3 \%)$ & $15(13.3 \%)$ & $26(16.1 \%)$ & \\
\hline Type of $\mathrm{COl}$ & & & & & $<0.001$ \\
\hline Academic & $1(4.3 \%)$ & $0(0.0 \%)$ & $2(1.8 \%)$ & $1(0.6 \%)$ & \\
\hline Financial/industry & $0(0.0 \%)$ & $1(1.3 \%)$ & $8(7.1 \%)$ & $17(10.6 \%)$ & \\
\hline None & $0(0.0 \%)$ & $8(10.4 \%)$ & $88(77.9 \%)$ & $117(72.7 \%)$ & \\
\hline Unknown & $22(95.7 \%)$ & $68(88.3 \%)$ & $15(13.3 \%)$ & $26(16.1 \%)$ & \\
\hline Funding statement & & & & & $<0.001$ \\
\hline No funding & $0(0.0 \%)$ & $1(1.3 \%)$ & $22(19.5 \%)$ & $27(16.8 \%)$ & \\
\hline No funding statement & $19(82.6 \%)$ & $59(76.6 \%)$ & $41(36.3 \%)$ & $66(41.0 \%)$ & \\
\hline Declared funding & $4(17.4 \%)$ & $17(22.1 \%)$ & $50(44.2 \%)$ & $68(42.2 \%)$ & \\
\hline Type of funding & & & & & $<0.001$ \\
\hline Academic & $1(6.2 \%)$ & $3(3.9 \%)$ & $4(5.4 \%)$ & $26(24.5 \%)$ & \\
\hline Academic and industry & $0(0.0 \%)$ & $1(1.3 \%)$ & $10(13.5 \%)$ & $4(3.8 \%)$ & \\
\hline Industry & $3(8.8 \%)$ & $13(16.9 \%)$ & $36(48.6 \%)$ & $59(55.7 \%)$ & \\
\hline
\end{tabular}


Table 1 continued

\begin{tabular}{|c|c|c|c|c|c|}
\hline & $\begin{array}{l}2001 \\
n=23\end{array}$ & $\begin{array}{l}2006 \\
n=77\end{array}$ & $\begin{array}{l}2011 \\
n=113\end{array}$ & $\begin{array}{l}2016 \\
n=161\end{array}$ & $P$ value \\
\hline None & $0(0.0 \%)$ & $1(1.3 \%)$ & $22(29.7 \%)$ & $17(16.0 \%)$ & \\
\hline Not declared & $12(75.0 \%)$ & $59(76.6 \%)$ & $2(2.7 \%)$ & $0(0.0 \%)$ & \\
\hline Number of grant declared & $0.00(0.00,0.00)$ & $0.00(0.00,0.00)$ & $1.00(0.00,2.00)$ & $1.00(0.00,1.00)$ & $<0.001$ \\
\hline Number of authors affiliated with industry & $0.00(0.00,0.50)$ & $0.00(0.00,0.00)$ & $0.00(0.00,0.00)$ & $0.00(0.00,0.00)$ & $<0.001$ \\
\hline
\end{tabular}

$I Q R$ inter-quartile range, ICU intensive care unit, $R C T$ randomized controlled trial, SR/MA systematic review/meta-analysis, $C O I$ conflict of interest

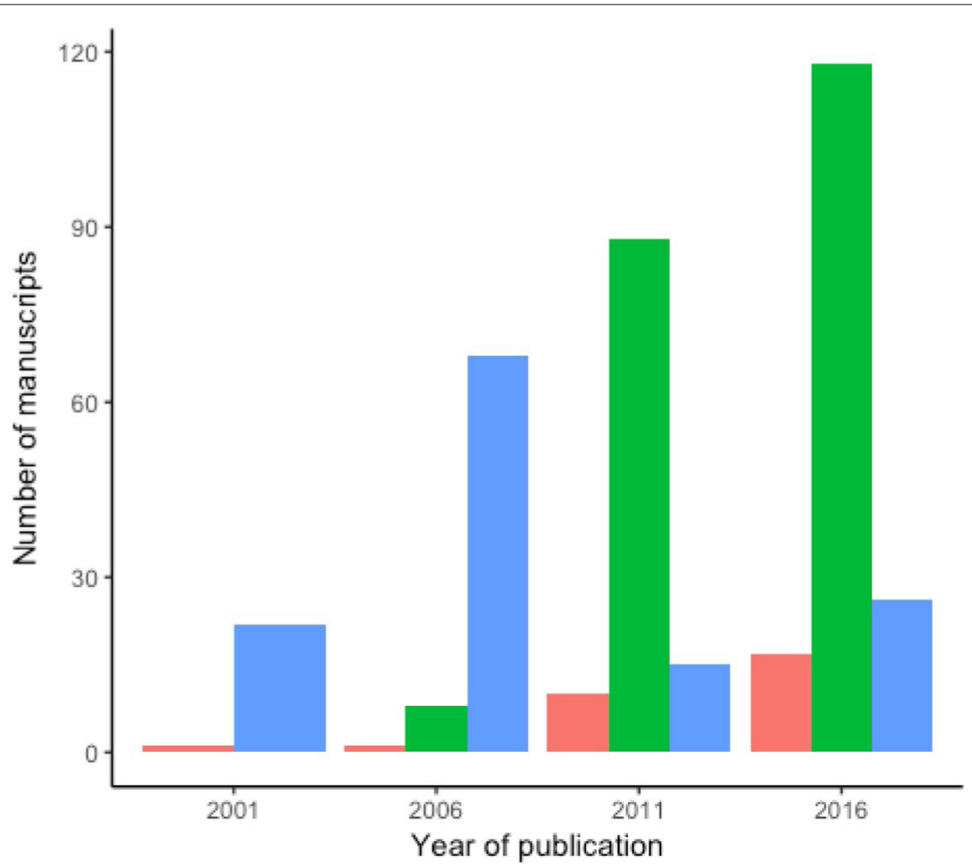

COI Statement

Declared COI

Declared absence of $\mathrm{COI}$

No Statement

Fig. 2 Rate of statements (declared COI, declared absence of COI and absence of statement) by publication year

\section{Factors independently associated with declared COI}

In order to assess factors independently associated with declared COI (Fig. 5), and as the number of events was limited, the year variable was transformed into a binary variable (before and after 2010). After adjustment for potential confounders, declared COI were more frequent in 2011-2016 (OR 4.06; 95\% CI 1.15-25.79) and in the fourth quartile of IF (OR of 16.73; 95\% CI 3.28-306.20). No correlation or interaction between explanatory variables was detected and variance inflation factor was lower than 1.5. Hosmer-Lemeshow goodness of fit C-stat test was performed $(P$ value $=0.99)$.

\section{Sensitivity analyses}

A sensitivity analysis was conducted. Three variables were one by one forced into the primary model, particularly: focus of the study, country of the first author and/ or endorsement of the study by a trial group. This did not change the final model and the results.

\section{Post hoc sensitivity analysis in a larger dataset}

The limited sample size in 2001 and 2006 was unexpected. We, therefore, conducted a post hoc sensitivity analysis in which we added two additional months for the 2001 period and 1 month for the 2006 period. Overall, 120 and 134 articles were analyzed for 2001 and 2006, respectively (Fig. S4 and table S2). Relatively to the rate and independent predictors of COI statement, results were similar to those obtained with the main analysis (Figs. S5, S6, and S7).

\section{Discussion}

The main findings of our study is that COI disclosures in critical care studies increased over the past 15 years, but also the rate of COI among these declarations. COI statements were thus found in two thirds of the evaluated studies, which is lower than previously reported [18, 19]. Qureshi et al. [18] evaluated 1574 articles published in 2009 and found a COI statement in $77 \%$ of the articles, 
Table 2 Characteristics of journals and studies according to COI statement [reported as number (\%) or median (IQR)]

\begin{tabular}{|c|c|c|c|c|}
\hline & $\begin{array}{l}\text { Declared COI } \\
n=29\end{array}$ & $\begin{array}{l}\text { No COI declared } \\
n=214\end{array}$ & $\begin{array}{l}\text { No statement } \\
n=131\end{array}$ & $P$ value \\
\hline Year of publication & & & & $<0.001$ \\
\hline 2001 & $1(3.4 \%)$ & $0(0.0 \%)$ & $22(16.8 \%)$ & \\
\hline 2006 & $1(3.4 \%)$ & $8(3.7 \%)$ & $68(51.9 \%)$ & \\
\hline 2011 & $10(34.5 \%)$ & $88(41.1 \%)$ & $15(11.5 \%)$ & \\
\hline 2016 & $17(58.6 \%)$ & $118(55.1 \%)$ & $26(19.8 \%)$ & \\
\hline \multicolumn{5}{|c|}{ Journal and publishers' characteristics } \\
\hline Continent & & & & 0.013 \\
\hline Africa & $0(0.0 \%)$ & $1(0.5 \%)$ & $0(0.0 \%)$ & \\
\hline Asia & $0(0.0 \%)$ & $6(3.2 \%)$ & $6(5.3 \%)$ & \\
\hline Australia & $0(0.0 \%)$ & $3(1.6 \%)$ & $1(0.9 \%)$ & \\
\hline Europe & $12(44.4 \%)$ & $81(43.3 \%)$ & $40(35.1 \%)$ & \\
\hline N. America & $14(51.3 \%)$ & $86(46.0 \%)$ & $60(52.7 \%)$ & \\
\hline Oceania & $0(0.0 \%)$ & $2(1.1 \%)$ & $3(2.6 \%)$ & \\
\hline South America & $1(3.7 \%)$ & $8(4.3 \%)$ & $4(3.5 \%)$ & \\
\hline Type of journal & & & & 0.001 \\
\hline Generalist & $14(48.3 \%)$ & $90(42.1 \%)$ & $36(27.5 \%)$ & \\
\hline $\mathrm{ICU}$ & $13(44.8 \%)$ & $64(29.9 \%)$ & $35(26.7 \%)$ & \\
\hline Other & $1(3.4 \%)$ & $23(10.7 \%)$ & $17(13.0 \%)$ & \\
\hline Non ICU specialist & $1(3.4 \%)$ & $37(17.3 \%)$ & $43(32.8 \%)$ & \\
\hline Open journal & $8(27.6 \%)$ & $58(27.1 \%)$ & $17(13.3 \%)$ & 0.010 \\
\hline Impact factor & $4.42(2.31,6.60)$ & $2.06(1.42,3.56)$ & $1.46(0.35,2.28)$ & $<0.001$ \\
\hline \multicolumn{5}{|l|}{ Study characteristics } \\
\hline Type of study & & & & 0.043 \\
\hline Other & $25(86.2 \%)$ & $205(95.8 \%)$ & $129(98.5 \%)$ & \\
\hline $\mathrm{RCT}$ & $3(10.3 \%)$ & $6(2.8 \%)$ & $1(0.8 \%)$ & \\
\hline SR/MA & $1(3.4 \%)$ & $3(1.4 \%)$ & $1(0.8 \%)$ & \\
\hline Focus of the study & & & & 0.084 \\
\hline Device & $4(13.8 \%)$ & $19(8.9 \%)$ & $10(7.6 \%)$ & \\
\hline Drugs & $0(0.0 \%)$ & $11(5.1 \%)$ & $15(11.5 \%)$ & \\
\hline Other & $18(62.1 \%)$ & $121(56.5 \%)$ & $80(61.1 \%)$ & \\
\hline Strategy & $7(24.1 \%)$ & $63(29.4 \%)$ & $26(19.8 \%)$ & \\
\hline Review or editorial & $1(3.4 \%)$ & $25(11.7 \%)$ & $16(12.2 \%)$ & 0.380 \\
\hline Study sample & $359(99.5,6225.5)$ & $150(33.5,746.5)$ & $127.5(23,1016)$ & 0.061 \\
\hline Statistical significance & $14(48.3 \%)$ & $64(29.9 \%)$ & $20(15.3 \%)$ & $<0.001$ \\
\hline Number of authors & $6(5,10)$ & $5.00(4,6)$ & $4(2,6)$ & $<0.001$ \\
\hline Study endorsed by trial group & $5(17.2 \%)$ & $14(6.5 \%)$ & $11(8.4 \%)$ & 0.135 \\
\hline \multicolumn{5}{|l|}{ Col and funding } \\
\hline Type of COI & & & & $<0.001$ \\
\hline Academic & $4(13.8 \%)$ & $0(0.0 \%)$ & $0(0.0 \%)$ & \\
\hline Financial/industry & $25(86.2 \%)$ & $1(0.5 \%)$ & $0(0.0 \%)$ & \\
\hline None & $0(0.0 \%)$ & $213(99.5 \%)$ & $0(0.0 \%)$ & \\
\hline Unknown & $0(0.0 \%)$ & $0(0.0 \%)$ & $131(100.0 \%)$ & \\
\hline Funding statement & & & & $<0.001$ \\
\hline No funding & $1(3.4 \%)$ & $46(21.5 \%)$ & $3(2.3 \%)$ & \\
\hline No statement & $4(13.8 \%)$ & $80(37.4 \%)$ & $101(77.1 \%)$ & \\
\hline Funding declared & $24(82.8 \%)$ & $88(41.1 \%)$ & $27(20.6 \%)$ & \\
\hline Type of funding & & & & $<0.001$ \\
\hline Academic & $7(28.0 \%)$ & $21(13.8 \%)$ & $6(6.2 \%)$ & \\
\hline Academic and industry & $5(20.0 \%)$ & $9(5.9 \%)$ & $1(1.0 \%)$ & \\
\hline
\end{tabular}




\begin{tabular}{lccc} 
& $\begin{array}{l}\text { Declared COI } \\
n=29\end{array}$ & $\begin{array}{l}\text { No col declared } \\
n=214\end{array}$ & $\begin{array}{c}\text { No statement } \\
n=131\end{array}$ \\
\hline Industry & $12(48.0 \%)$ & $79(52.0 \%)$ & $20(20.8 \%)$ \\
None & $1(4.0 \%)$ & $36(23.7 \%)$ & $3(3.1 \%)$ \\
Unknown & $0(0.0 \%)$ & $7(4.6 \%)$ & $66(68.8 \%)$ \\
Number of declared grant & $1.00(1.00,2.00)$ & $1.00(0.00,1.00)$ & $0.00(0.00,1.00)$ \\
Number of authors affiliated to industry & $0.00(0.00,2.00)$ & $0.00(0.00,0.00)$ & $<0.001$ \\
\hline
\end{tabular}

$I Q R$ inter-quartile range, ICU intensive care unit, $R C T$ randomized controlled trial, SR/MA systematic review/meta-analysis, COI conflict of interest

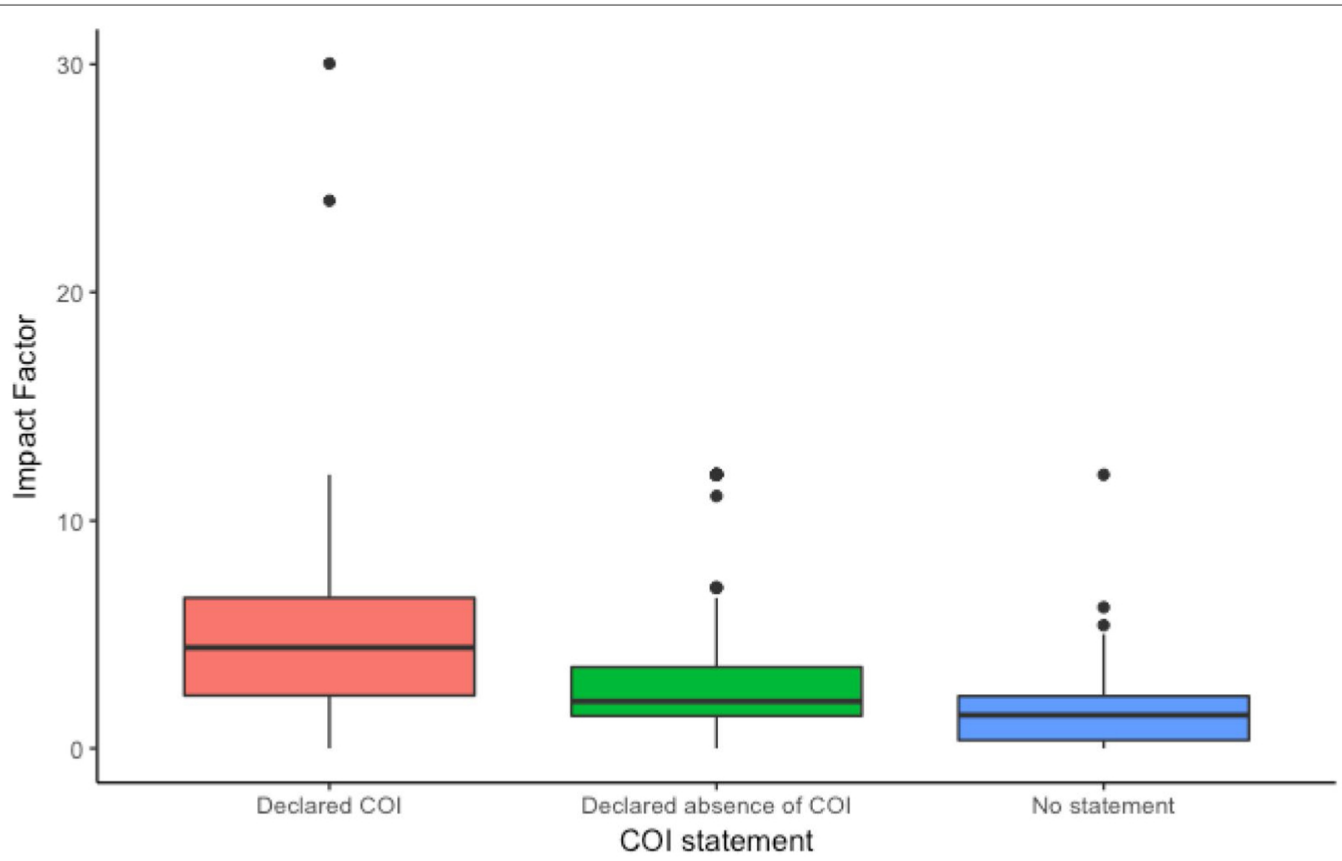

Fig. 3 Boxplot reporting impact factor of journal according to COI statement

while Hakoum et al. [19]. included 200 randomized controlled trials published in 2015 and showed that 94\% had COI statements. Disclosures of COI were, however, found to widely vary across specialties [19]. The methods (survey versus systematic review), the type of articles considered (RCT, meta-analyses or guidelines), the year of publication and the perception about what constitutes a conflict of interest may account for this variations in prevalence of COI disclosure [20,21].

Not surprisingly, we found a significant increase in the reporting of COI over time. While statements were nearly non-existent in 2001 and 2006, they have widely increased over the last decade. This is consistent with two successive studies in leading journals of gastroenterology and hepatology $[18,22]$. This increase probably resulted from several organizations developing guidelines for the handling of $\mathrm{COI}$ in biomedical research, including
WAME [9]. Nevertheless, the rate of missing statements about funding sources and $\mathrm{COI}$ disclosures remains high in 2016 (41.0\% and $16.1 \%$, respectively).

Our results also highlight the significant reduction in the discrepancy between disclosed COI and affiliation with industry over time, which may be a result of more rigorous COI policies by scientific journals. Although no direct comparison of COI statement with actual COI was feasible, COI under-declaration was suggested by the rate of discordance between declared affiliation to industry and declared COI.

In the present systematic review, one of the factors independently associated with COI statements was publication in the most recent years (2011 and 2016). Not only did COI disclosure increase over time, but also the rate of COI among these declarations. Indeed, 2011 and 2016 were independently associated with increased rate 


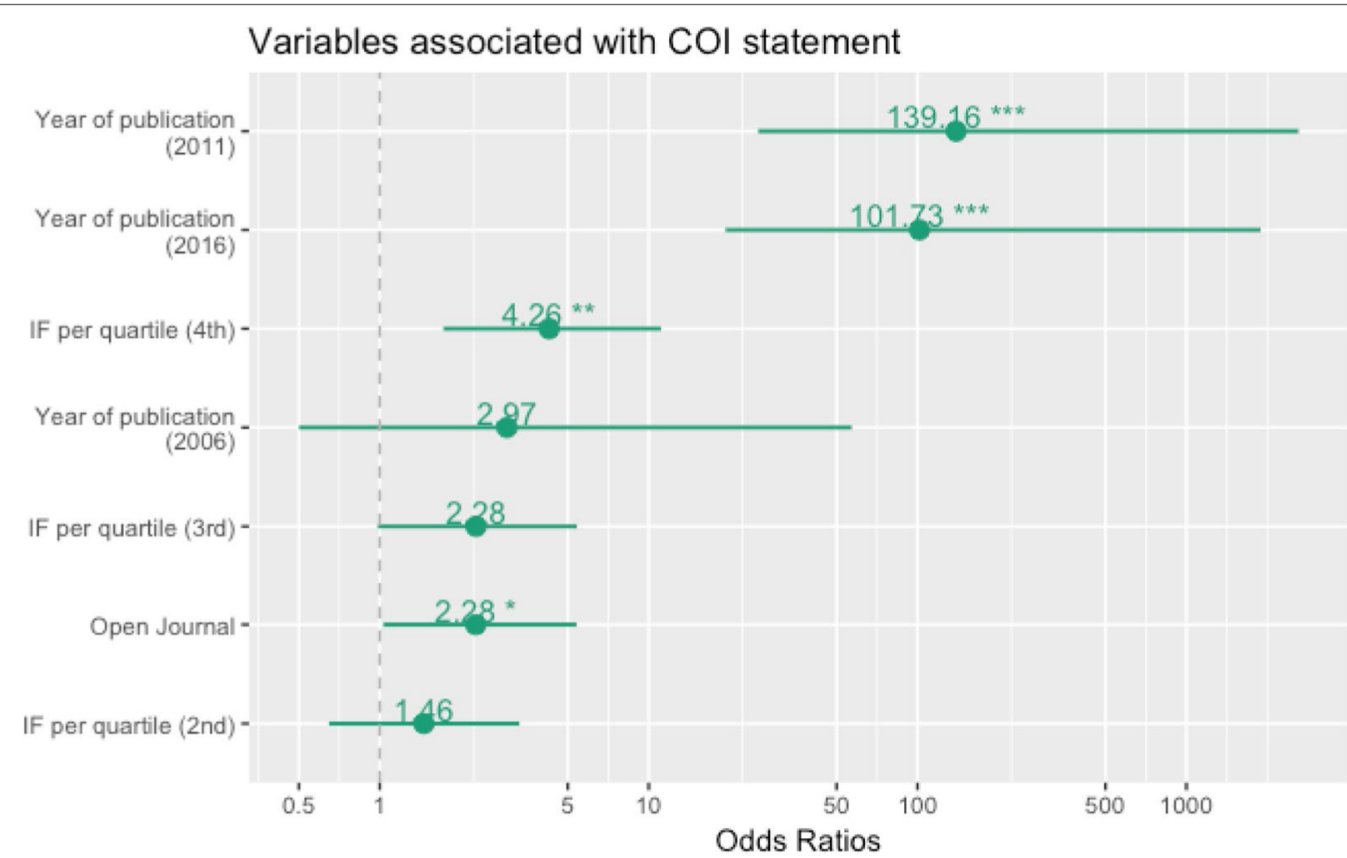

Fig. 4 Forest plot reporting adjusted odds ratios (ORs) (95\% Cl) of variables ultimately retained in the logistic regression model assessing presence of COI statement. Area under the ROC curve of the final model was 0.85

\section{Variables associated with self-reported COI}

(OR-95\% Cl)

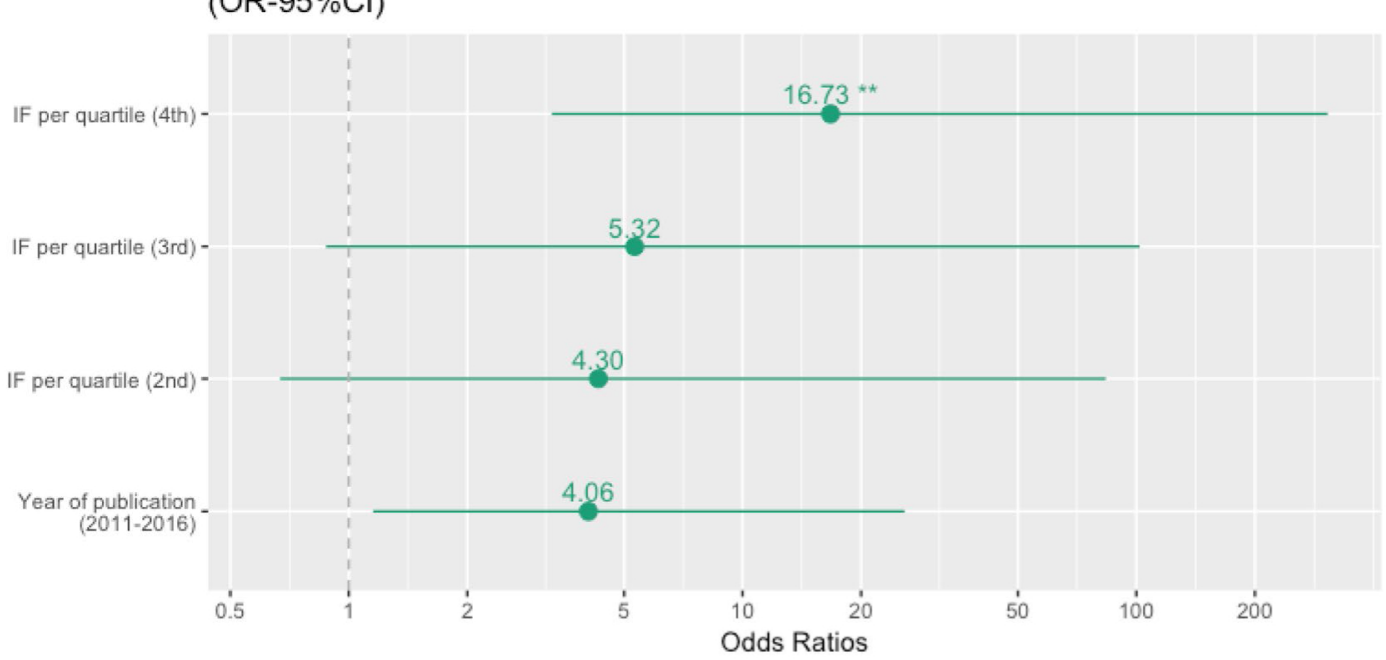

Fig. 5 Forest plot reporting adjusted odds ratios ( $95 \% \mathrm{Cl}$ ) of variables ultimately retained in the logistic regression model assessing presence of self-reported $\mathrm{COI}$

of COI. This finding along with the lower rate of discordance suggests that COI were underreported in 2001 and 2006, and indirectly reflects an under-reporting of actual COI. Our results on the reporting of financial COI are consistent with other recent surveys. Hakoum et al. [19] compared 19 surveys on COI of authors from several types of trials and showed discrepancies between surveyed field, with highest COI disclosures in oncology research. Beyari et al. [23] also reported that papers published more recently were more likely to report on the 
presence or absence of a conflicts of interest. In the present study, the COI rate was much lower than previously reported [19]. Hakoum et al. indeed showed as much as $57 \%$ of the 188 trials having at least one author reporting at least one COI and the totality of these trials having at least one author reported financial COI [19]. The results suggest a selection bias in these studies reporting highquality RCTs, published in higher rank journal having a higher rate of COI statement. Our study included only ten RCTs of 374 included articles. Despite the small sample, there was an increased proportion of declared COI compared to other ICU articles. Interestingly, disclosures about both academic and financial COI and funding have considerably increased over time, although academic COI remain less frequently reported than financial ones. In line with our findings, several already older studies reported rate of spontaneous under-reporting and impact of recommendations in other specialties [6, 24-27].

Not surprisingly, the higher the impact factor was, the higher the rates of COI statements and of COI declared, which is consistent with previous data [19]. This association results probably from more stringent disclosure policies in journals with higher impact factors, constraining the authors to declare their COI. Most of the large multicenter trials have authors reporting COI, which may be acceptable as long as COI are clearly disclosed.

Rose et al. [28] showed that authors who performed key roles in the design, analysis, and reporting of oncology clinical trials are more likely to have financial ties to industry. However, industry may be involved in some trial design, reporting and decision to publish, which should be clearly established, as it has been clearly shown that there were significant associations between industry sponsorship and pro-industry conclusions and restrictions on publication [4].

The strengths of our study include the following: we included a large number of intensive care studies (374 articles), and we assessed the quality of the data extractions by cross-checking $10 \%$ of the sample; also, the long time-period (15 years) considered allowed for data collection across numerous specialized and non-specialized journals, thus limiting the risk of the results being skewed by some practices or journals; finally, all the studies included were published after 2000, allowing for a recent assessment of $\mathrm{COI}$ and research funding practices in intensive care.

Our study also has limitations. First, the broad inclusion criteria were meant to include a sample representative of all ICU research. However, the inclusion of a large number of studies published in lower IF journals, as well as the few RCTs and reviews among the included studies, may have influenced our findings and may at least partly explain the low rate of COI reported. In addition, the increasing number of monthly published manuscript resulted in a limited sample size during the early years. We tried to acknowledge this by conducting a post hoc analysis in which we included a larger sample size for the years 2001 and 2006. Although the overall quality of our dataset was good, some variables were at least partly subjective and were found to be poorly reliable. Our study report a decrease in rate of missing COI statement and in discrepancy between declared COI and authors affiliation to industry, suggesting under-reporting of COI. Nevertheless, an increased rate of COI triggered by increased involvement of industry in research over time may have participated to the observed results and should probably be taken into account when interpreting our results. Moreover, the last part of our analysis was performed in 2016 , very early after launch of sunshine act in various countries [8]. Our study was, therefore, unable to assess impact of this initiative on COI reporting. Last, our study focused on financial COI although non-financial COI may occurs and are uncommonly reported. Importance of these non-financial COI, as well as their influence on study finding may deserve to be assessed by future studies.

Our study suggests COI reporting to have been unintuitive to most investigators and unreliable before ICMJE statements, and that strong incentives are needed to implement adequate reporting of COI. Considerable efforts should therefore be made in the next years to implement careful reporting of conflicts of interest of authors in intensive care studies and much work remains to be done to make disclosures uniform across journals. Several avenues for research emerge from our study. First, specific data regarding reliability of $\mathrm{COI}$ remain to be assessed and influence of COI on other actors of the editorial process (including peer reviewers and editors) to be evaluated. In addition, the high rate of $\mathrm{COI}$ in open access journals in our study was unexpected and may deserve further investigations. Last, the influence of initiative aiming to transparently report COI via dedicated website [8] on COI statements accuracy could not be assessed by this study. Future studies may be required as this regard.

\section{Abbreviations}

Cl: Confidence interval; COI: Conflict of interest; ICMJE: International Committee of Medical Journal Editors; ICU: Intensive care unit; IF: Impact factor; IOM: Institute of Medicine; IQR: Interquartile range; RCT: Randomized clinical trial; MESH: Medical subject headings; OR: Odds ratio; PRISMA: Preferred reporting items for systematic reviews and meta-analyses; ROC: Receiver operating char acteristic; SE: Standard error; SR/MA: Systematic review/meta-analysis; WAME: World Association of Medical Editors. 


\section{Author details}

${ }^{1}$ Medical ICU, Saint-Louis University Hospital, AP-HP, 1 Avenue Claude Vellefaux, 75010 Paris, France. ${ }^{2}$ Faculté de Médecine, Université Paris-Diderot, Sorbonne-Paris-Cité, Paris, France. ${ }^{3}$ ECSTRA team, Biostatistics and clinical epidemiology, UMR 1153 (center of epidemiology and biostatistic Sorbonne Paris Cité, CRESS), INSERM, Paris, France. ${ }^{4}$ Faculté de Médecine, Hôpitaux universitaires de Strasbourg, Service de réanimation, Nouvel Hôpital Civil, Université de Strasbourg (UNISTRA), Strasbourg, France. ${ }^{5}$ ImmunoRhumatologie Moléculaire, INSERM UMR_S1109, LabEXTRANSPLANTEX, Centre de Recherche d'Immunologie et d'Hématologie, Faculté de Médecine, Fédération Hospitalo-Universitaire (FHU) OMICARE, Fédération de Médecine Translationnelle de Strasbourg (FMTS), Université de Strasbourg, Strasbourg, France. ${ }^{6}$ PhyMedExp, INSERM, CNRS, CHU de Montpellier, Département d'anesthésie-réanimation Saint-Eloi, Université de Montpellier, 80, avenue Augustin-Fliche, 34295 Montpellier Cedex, France. ${ }^{7}$ Department of Intensive Care, Copenhagen University Hospital-Rigshospitalet, Blegdamsvej 9, 2100 Copenhagen, Denmark. ${ }^{8}$ Department of Anaesthesiology and Intensive Care, Zealand University Hospital, Lykkebækvej 1, 4600 Køge, Denmark. ${ }^{9}$ Department of Anesthesia and Critical Care, Beaujon University Hospital, AP-HP, Paris, France. ${ }^{10}$ Department of Anesthesia and Critical Care, Niguarda Hospital, University of MilanBicocca, Milan, Italy. ${ }^{11}$ Intensive Care Unit, Hospital da Mulher, Salvador, Brazil.

\section{Funding}

None.

\section{Compliance with ethical standards}

\section{Conflicts of interest}

A De Jong reports personal fees from Baxter and Medtronic-Covidien, and travel reimbursements from Fresenius-Kabi, MSD France, Astellas, Pfizer and Fisher Paykel. J. Helms reports congress and travel reimbursements from Pfizer, Diagnostica Stago, MSD France, Astrazeneca and Gilead Sciences. E. Weiss reports personal fees form Baxter, MSD France and Biomerieux, and travel reimbursements from MSD France and Eumedica. M. Darmon reports having received research support from MSD and from ASTUTE medical, speaker fees from MSD, Astellas and Bristol-Myers-Squibb, support to organize educational meeting from MSD, Astellas, and Jazz Pharma and having participated to an advisory board from SANOFI-AVENTIS. M. Hylander Møller, N. Buhl Hjortrup, A. Granholm and M. Warrer Petersen declare that their department has received research grants from Fresenius Kabi, CSL Bering and Ferring Pharmaceuticals. Elie Azoulay reports having received fees for lectures from Alexion, Gilead, and Baxter. His institution and research group have received support from Fisher \& Payckle, Pfizer, Ablkynx, MSD and Jazz Pharma. Other authors declare having no COI to declare.

\section{References}

1. Ferris LE, Fletcher RH (2010) Conflict of interest in peer-reviewed medical journals: the World Association of Medical Editors (WAME) position on a challenging problem. Neurosurgery 66:629-630. https://doi. org/10.1227/01.neu.0000369904.38343.e4

2. Lemmens T (2004) Confronting the conflict of interest crisis in medical research. Monash Bioeth Rev 23:19-40

3. Friedman PJ (2002) The impact of conflict of interest on trust in science. Sci Eng Ethics 8:413-420

4. Bekelman JE, Li Y, Gross CP (2003) Scope and impact of financial conflicts of interest in biomedical research: a systematic review. JAMA 289:454-465

5. Elliott KC (2008) Scientific judgment and the limits of conflict-of-interest policies. Acc Res 15:1-29. https://doi.org/10.1080/08989620701783725

6. McCrary SV, Anderson CB, Jakovljevic J et al (2000) A national survey of policies on disclosure of conflicts of interest in biomedical research. $\mathrm{N}$ Engl J Med 343:1621-1626. https://doi.org/10.1056/NEJM20001130343 2207

7. Marušić A, Hren D, Mansi B et al (2014) Five-step authorship framework to improve transparency in disclosing contributors to industry-sponsored clinical trial publications. BMC Med 12:197. https://doi.org/10.1186/s1291 6-014-0197-z

8. Santhakumar S, Adashi EY (2015) The physician payment sunshine act: testing the value of transparency. JAMA 313:23-24. https://doi. org/10.1001/jama.2014.15472

9. World Association of Medical Editors (2009) Conflict of interest in peerreviewed medical journals: a policy statement of the World Association of Medical Editors (WAME). J Child Neurol 24:1321-1323. https://doi. org/10.1177/0883073809345928

10. Cohen JJ (2002) Managing financial conflicts of interest in clinical research. Sci Eng Ethics 8:401-406

11. Rothman DJ, MCDonald WJ, Berkowitz CD et al (2009) Professional medical associations and their relationships with industry: a proposal for controlling conflict of interest. JAMA 301:1367-1372. https://doi.org/10.1001/ jama.2009.407

12. Steinbrook R (2009) Controlling conflict of interest-proposals from the Institute of Medicine. N Engl J Med 360:2160-2163. https://doi. org/10.1056/NEJMp0810200

13. Managing conflict of interest in $\mathrm{NHH}$ peer review of grants and contracts. https://grants.nih.gov/grants/peer/peer_coi.htm. Accessed 6 Aug 2018

14. Krimsky S, Rothenberg LS (1998) Financial interest and its disclosure in scientific publications. JAMA 280:225-226

15. Institute of Medicine (US) Committee on Potential Conflicts of Interest in Patient Outcomes Research Teams (1991) Patient outcomes research teams: managing conflict of interest. National Academies Press, Washington

16. Drazen JM, de Leeuw PW, Laine C et al (2010) Toward more uniform conflict disclosures-the updated ICMJE conflict of interest reporting form. N Engl J Med 363:188-189. https://doi.org/10.1056/NEJMe1006030

17. Liberati A, Altman DG, Tetzlaff J et al (2009) The PRISMA statement for reporting systematic reviews and meta-analyses of studies that evaluate healthcare interventions: explanation and elaboration. BMJ 339:b2700

18. Qureshi J, Sud A, Vakil N (2012) Funding source and conflict of interest disclosures by authors and editors in gastroenterology specialty journals revisited. Aliment Pharmacol Ther 35:690-695. https://doi.org/10.111 1/j.1365-2036.2011.04989.x

19. Hakoum MB, Jouni N, Abou-Jaoude EA et al (2017) Authors of clinical trials reported individual and financial conflicts of interest more frequently than institutional and nonfinancial ones: a methodological survey. J Clin Epidemiol 87:78-86. https://doi.org/10.1016/j.jclinepi.2017.04.002

20. Bindslev JBB, Schroll J, Gøtzsche PC, Lundh A (2013) Underreporting of conflicts of interest in clinical practice guidelines: cross sectional study. BMC Med Ethics 14:19. https://doi.org/10.1186/1472-6939-14-19

21. Rodwin MA (2018) Attempts to redefine conflicts of interest. Acc Res 25:67-78. https://doi.org/10.1080/08989621.2017.1405728

22. Bhargava N, Qureshi J, Vakil N (2007) Funding source and conflict of interest disclosures by authors and editors in gastroenterology specialty journals. Am J Gastroenterol 102:1146-1150. https://doi.org/10.111 1/j.1572-0241.2007.01268.x

23. Beyari MM, Strain D, Li CS, Lamfon HA (2014) Conflict of interest reporting in dentistry meta-analyses: a systematic review. J Clin Exp Dent 6:e280e285. https://doi.org/10.4317/jced.51225

24. Lo B, Wolf LE, Berkeley A (2000) Conflict-of-interest policies for investigators in clinical trials. N Engl J Med 343:1616-1620. https://doi. org/10.1056/NEJM200011303432206

25. Neuman J, Korenstein D, Ross JS, Keyhani S (2011) Prevalence of financial conflicts of interest among panel members producing clinical practice guidelines in Canada and United States: cross sectional study. BMJ 343:d5621

26. Choudhry NK, Stelfox HT, Detsky AS (2002) Relationships between authors of clinical practice guidelines and the pharmaceutical industry. JAMA 287:612-617

27. Campsall P, Colizza K, Straus S, Stelfox HT (2016) Financial relationships between organizations that produce clinical practice guidelines and the biomedical industry: a cross-sectional study. PLoS Med 13:e1002029. https://doi.org/10.1371/journal.pmed.1002029

28. Rose SL, Krzyzanowska MK, Joffe S (2010) Relationships between authorship contributions and authors' industry financial ties among oncology clinical trials. J Clin Oncol 28:1316-1321. https://doi.org/10.1200/ JCO.2008.21.6606 